\title{
Association between job strain and prevalence of hypertension: a cross sectional analysis in a Japanese working population with a wide range of occupations: the Jichi Medical School cohort study
}

\author{
A Tsutsumi, K Kayaba, K Tsutsumi, M Igarashi, on behalf of the Jichi Medical School \\ Cohort Study Group
}

\begin{abstract}
Objectives-To explore the association between the prevalence of hypertension in a Japanese working population and job strain (a combination of low control over work and high psychological demands), and to estimate this association in different sociodemographic strata.

Methods-From a multicentre community based cohort study of Japanese people, sex specific cross sectional analyses were performed on 3187 men and 3400 women under 65 years of age, all of whom were actively engaged in various occupations throughout Japan. The baseline period was 1992-4. The association between job characteristics-measured with a Japanese version of the Karasek demand-control questionnaire-and the prevalence of hypertension defined by blood pressure and from clinical diagnoses were examined. Adjustments were made for possible confounders. The analyses were repeated for stratified categories of occupational class, educational attainment, and age group.
\end{abstract}

Results-In men, the level of job strain (the ratio of psychological job demands to job control) correlated with the prevalence of hypertension. In a multiple logistic regression model, job strain was significantly related to hypertension (odds ratio $1.18 ; 95 \%$ confidence interval 1.05 to 1.32), after adjustment for age, employment (white collar $v$ blue collar), marital status, family history of hypertension, cigarette smoking, alcohol intake, physical activity, and body mass index. The stratified analyses showed significant excess risks in the subordinate groups compared with managers, blue collar workers, less educated workers, and the older age groups. This association was not significant in women. Multiple linear regression analyses, with systolic and diastolic blood pressures as dependent variables, did not show any significant association.

Conclusions-The findings provided limited proof that job strain is related to hypertension in Japanese working men. Older men in a lower social class may be more vulnerable to the hypertensive effects of job strain.

(Occup Environ Med 2001;58:367-373)
Keywords: hypertension; stress; psychological; work

Comprehensive reviews conclude that job strain, a combination of low control over the job and high psychological demands, is related to the incidence and prevalence of cardiovascular diseases in western countries. ${ }^{1-3}$ It was postulated that one of the underlying mechanisms through which job strain leads to cardiovascular diseases is high blood pressure due to chronic physiological arousal. ${ }^{2}$ Several studies have been conducted to substantiate this hypothesis; and evidence has been accumulating to prove a cause-effect relation between job strain and high blood pressure. ${ }^{4-8}$ However, the results have not been completely consistent. ${ }^{9-13}$ Also, cross cultural evidence has been very limited. $^{2}$

It might be expected that a clearer association between job strain and hypertension would emerge in some social strata. Occupational class and educational level are variables to be taken into consideration. ${ }^{14}$ Low occupational class has often been reported to be associated with high blood pressure. ${ }^{15}{ }^{16}$ Other levels of social class and education may also determine levels of blood pressure independently or together from work conditions. ${ }^{9}$ Many researchers have controlled for these variables, if taken into account, in their statistical analyses, but a stratified analysis has seldom been done. Furthermore, a sex difference seems to exist in the association between job strain and blood pressure. Light et $a l^{17}$ and Niedhammer et $a l^{18}$ (not job strain, but job control) reported a positive association in men but not in women, whereas positive associations in women were found by others. ${ }^{19}{ }^{20}$ Age differences have also been suggested. The effect that job strain has on blood pressure seems to be more likely in the older age groups. ${ }^{611}$ Sampling from a diverse population would be appropriate to determine in which populations the most prominent effects of job strain will emerge.

The Jichi Medical School cohort study, a multicentre community based cohort study, which is designed to explore coronary risk factors in the Japanese people, provides the tools to examine whether job strain is associated with the prevalence of hypertension among male and female Japanese workers across various occupations. This was tested for some sociodemographic categories in non-western occupational settings. 


\section{Methods}

The aim of the Jichi Medical School cohort study was to investigate the risk factors for cardiovascular disease in Japan. Data were collected between 1992 and 1994. Ultimately, 12490 Japanese workers from 12 rural communities across Japan participated..$^{21}{ }^{22}$ In Japan in accordance with the Health and Medical Service Law for the Aged, mass screening examinations for cardiocerebrovascular diseases have been conducted since 1983. The subjects for these examinations were residents with ages between 30 and 69 years in four of the 12 communities and between 40 and 69 years in the other eight. In each community, the local government office sent letters to all potential participants inviting them to take part in the programme. The invitation mentioned that people who were visiting hospitals or clinics because of cardiovascular diseases did not have to take the examination. The overall response rate was $65.4 \%$. People other than those involved in these age groups $(n=282$ for the younger age group and 699 for those over 69), who voluntarily participated in the study were included in the database. The final database comprised 4911 men and 7579 women.

\section{PROCEDURE}

Sociodemographic and behavioural variables were investigated through a standardised questionnaire, which requested information on age, occupational environment, marital status, education, family medical history, smoking, alcohol consumption, and physical activity. The questionnaire was given to the participants to complete on their own before the physical examination. Informed consent was obtained from all prospective participants.

The physical examinations took place in each community. Height was measured without shoes. Body weight was recorded with the subject clothed, and $0.5 \mathrm{~kg}$ in summer or $1 \mathrm{~kg}$ in the other seasons was subtracted from the recorded weight. Body mass index was calculated as weight $(\mathrm{kg}) /$ height $(\mathrm{m})^{2}$. The systolic and diastolic blood pressures were measured with a fully automated sphygmomanometer (BP203RV-II, Nippon Colin, Komaki, Japan), which was placed on the right arm of the subject, after he or she had been sitting for $5 \mathrm{~min}$ utes. People were classified as hypertensive if (a) their systolic blood pressure was equal to or greater than $160 \mathrm{~mm} \mathrm{Hg}$, (b) their diastolic blood pressure was equal to or greater than 90 $\mathrm{mm} \mathrm{Hg}$, or (c) they had been clinically diagnosed as hypertensive. The last group included not only patients who were on antihypertensive medication but also those who were undergoing treatment other than drug treatment. It was decided to use this definition; however, separate analyses, with this criterion including only those who took medication, gave us similar results.

Two scales were used to define job characteristics - psychological job demands and job control. Psychological job demands was defined by five elements (work fast, work hard, demand for extra work, insufficient time to do work, and conflicting demands). Job control was defined as the sum of two subscales that were given equal weight: (a) skill discretion, measured by four elements (continuous need to acquire new knowledge, skill requirement, requirement for creativity, and repetitiveness); and (b) decision authority, measured by two elements (freedom to make decisions and choice in the approach to work). The psychometric property of the Japanese version of the demand-control questionnaire has been reported elsewhere. ${ }^{23}{ }^{24}$ All questions were scored on a Likert scale of 1 to 4 . Cronbach's coefficient $\alpha$ for the psychological demands index was 0.70 and for the job control index it was 0.64 for our sample. Job strain was defined as the ratio of demands to job control. Participants were grouped into one of three strata for each job characteristics index (low, medium, or high) based on tertiles, defined according to the distribution of scores in the total working population, and separately for men and women.

The following variables were selected as potential confounders: (a) age, <35, 36-45, 46-55, and 56-65; (b) job, managerial (self employed or a manager in their company) or not, and employment of white collar versus blue collar; (c) work hours, the number of hours spent at work on any given weekday; $(d)$ marital status, currently married or single; $(e)$ educational attainment, lower or higher than the level of compulsory education; $(f)$ family history of hypertension, positive if participant's mother or father had ever had high blood pressure; $(g)$ smoking habits, never smoked, ex-smoker, 1-20 cigarettes/day, or $\geqslant 21$ cigarettes/day for men, and never smoked, ex-smoker, or current smoker for women; $(h)$ alcohol intake, non-drinker, $<1$ go daily $\left(g_{0}=\mathrm{a}\right.$ traditional Japanese alcohol unit, 1 go $=28.9 \mathrm{~g}$ alcohol), 1-3 go daily (28.9-86.6 g alcohol), or $\geqslant 3$ go daily ( $\geqslant 86.7 \mathrm{~g}$ alcohol) for men, and non-drinker or current drinker for women; $(i)$ physical activity index ${ }^{25}$ low $(\leqslant 28)$, medium $(29-36)$, or high $(\geqslant 37)$; and $(j)$ body mass index, categorised into tertiles based on the total sample distribution $(<21.6,21.6-23.9$, or $\geqslant 24.0 \mathrm{~kg} / \mathrm{m}^{2}$ ).

\section{STUDY POPULATION}

The study population was restricted to actively working men and women under 65 because the aim of this analysis was to find the association between job characteristics and the prevalence of hypertension. A total of 6994 men and women who were employed and had a record of hypertension (from their medical history or blood pressure measured at the medical examination) were subjected to the analysis. Ninety four per cent of this sample completed the occupational psychosocial questionnaire, giving a final study population of 3187 male and 3400 female workers for whom both the blood pressure and questionnaire data were available. The following occupations were included: farming or forestry $(\mathrm{n}=954$ men, 1093 women); fishery (236, 34); security (19, 1); transportation $(85,4)$; construction $(607,84)$; production (336, 654); business (247, 356); 
office work (196, 333); professional $(199,193)$; service industry $(251,547)$; and unclassified $(57,101)$. The first six groups were designated blue collar occupations and the next four categories, white collar occupations. More than $99 \%$ of the workers were either self employed or employed by companies with less than 300 employees, which may be representative of the current industrial structure in Japan. ${ }^{26}$ Those who were employed on a part time basis may have been included in the study population, but this was not ascertained.

A comparison of the people who completed the job characteristics questionnaire with those who did not, showed that those who did not were older, had a lower educational level, were more likely to be employed as blue collar workers, and were slightly more likely to have hypertension than those who did.

\section{STATISTICS}

Sex specific analyses were performed. Comparisons among sociodemographic, behavioural, and job characteristics were done with the $\chi^{2}$ test and analysis of variance (ANOVA). Because hypertension was highly correlated with age, comparisons on hypertension were adjusted for age by the Mantel extension method. Only reported work hours (continuous variable) were compared by analysis of covariance (ANCOVA) with an adjustment for age. The age adjusted prevalence for each defined category was shown.

A logistic regression model was developed with hypertension as the outcome variable. Only age and the variables that were correlated with hypertension in the bivariate analyses were included as independent variables. For logistic regression analyses, job strain was coded from 1 to 3 , from a low to high level of strain. Participants with missing values for covariates in the adjusted multiple logistic model were excluded from that particular analysis. Because adjustment for the areas under study did not substantially change the association between job strain and hypertension, the variable was excluded from the analyses. Analyses classified by job and employment, educational attainment, and age (younger $v$ older) were also performed. Multiple linear regression was used when mean systolic and

Table 1 Mean job characteristics scores according to sociodemographic characteristics, stratified by job, employment, education, and age

\begin{tabular}{|c|c|c|c|c|c|c|c|c|}
\hline & \multicolumn{4}{|l|}{ Men } & \multicolumn{4}{|c|}{ Women } \\
\hline & $n$ & Demand & Control & Strain & $n$ & Demand & Control & Strain \\
\hline $\begin{array}{l}\text { All participants } \\
\text { Job: }\end{array}$ & 3187 & 11.9 & 16.9 & 0.718 & 3400 & 10.8 & 14.9 & 0.753 \\
\hline \multicolumn{8}{|l|}{ Job: } & $0.744^{\star \star}$ \\
\hline Subordinate & 1290 & 11.5 & 16.1 & 0.736 & 2029 & 10.7 & 14.5 & 0.768 \\
\hline \multicolumn{9}{|l|}{ Employment: } \\
\hline White Collar & 893 & $12.1^{\star \star}$ & $17.4^{\star \star \star}$ & $0.705^{\star \star}$ & 1429 & $10.6^{\star \star}$ & $15.3^{\star \star \star}$ & $0.718^{\star}$ \\
\hline Blue Collar & 2241 & 11.8 & 16.7 & 0.724 & 1931 & 10.9 & 14.7 & 0.778 \\
\hline \multicolumn{9}{|l|}{ Education: } \\
\hline Less than compulsory & 1253 & 11.8 & $16.5^{\star \star \star}$ & $0.732^{\star \star \star}$ & 1466 & 10.7 & $14.7^{\star \star \star}$ & $0.764^{\star}$ \\
\hline Higher & 1912 & 11.9 & 17.2 & 0.708 & 1920 & 10.8 & 15.1 & 0.743 \\
\hline \multicolumn{9}{|l|}{ Age group: } \\
\hline$\leqslant 55$ & 1863 & $12.2^{\star \star \star}$ & $17.3^{\star \star \star}$ & 0.718 & 2133 & $11.0^{\star \star \star}$ & 15.0 & $0.761^{\star \star}$ \\
\hline $56-65$ & 1324 & 11.5 & 16.4 & 0.718 & 1267 & 10.5 & 14.8 & 0.738 \\
\hline
\end{tabular}

${ }^{\star} \mathrm{p}<0.05 ;{ }^{\star \star} \mathrm{p}<0.01 ;{ }^{\star \star \star} \mathrm{p}<0.001$

Gender differences were all $\mathrm{p}<0.001$

ANOVA was performed among the categories. diastolic blood pressures were the outcome. All statistics were two tailed and values $p<0.05$ were considered to be significant.

\section{Results}

The mean (SD, range) age of the study population was $50.8(10.4,18-65)$ for men and $50.8(9.4,19-65)$ for women. There were more single men than single women. Compared with women, more men had attained a higher managerial status or were engaged in blue collar occupations, worked longer hours, and listed higher educational levels. Men smoked and consumed alcohol much more than women. The physical activity level was also higher for men than women (all $\mathrm{p}<0.01$ ).

The job characteristics scores, according to sex and selected variables, are shown in table 1 . Men had higher job demands and job control scores than women. Because of a substantial difference in the level of job control, the job strain level (the ratio of demands to control) was significantly higher for women than men. The younger men and women had higher job demand scores than the similarly placed older workers. The job control score was higher for younger than older men, thus both groups yielded the same level of strain. Younger women workers had higher strain scores than the older women. In both sexes, similar trends were found within the same occupational strata and level of educational attainment. With the exception of job demands for women, workers in managerial jobs and employment as white collar workers had higher demands and control scores than their respective counterparts. Better educated workers had higher control scores. The level of strain was significantly higher for the subordinates, blue collar workers, and those who were less educated.

According to the hypertension criterion, its prevalence in our sample was $25.1 \%(n=790)$ for men and $18.6 \%(n=631)$ for women. When compared with a representative population in Japan, the sample used here seemed to have lower blood pressure levels. ${ }^{27}$

Table 2 shows the prevalence of hypertension and normotension for the respective groups with selected variables. The prevalence of hypertension rose with increasing age for both sexes. In men, the age adjusted prevalence of hypertension was higher for those employed as white collar workers, those who were unmarried, had a family history of hypertension, were ex-smokers, consumed more alcohol, were physically more inactive, and were heavier than their respective counterparts. Similar associations were found in women for family history of hypertension, physical activity, and body mass index. However, hypertension in women was more common in less well educated women and in smokers. Marital status or alcohol intake was not associated with the prevalence of hypertension among women.

For men, the prevalence of hypertension increased as the level of job control decreased and the levels of psychological demands and job strain increased. Only the association between job strain and the prevalence of 
Table 2 Association among studied variables and hypertension

\begin{tabular}{|c|c|c|c|c|c|c|c|c|}
\hline \multirow[b]{2}{*}{ Variables } & \multicolumn{4}{|l|}{ Men } & \multicolumn{4}{|l|}{ Women } \\
\hline & $\begin{array}{l}\text { Hypertension } \\
\%(n)\end{array}$ & $\begin{array}{l}\text { Normotension } \\
\%(n)\end{array}$ & $\chi^{2}$ & $p$ Value & $\begin{array}{l}\text { Hypertension } \\
\%(n)\end{array}$ & $\begin{array}{l}\text { Normotension } \\
\%(n)\end{array}$ & $\chi^{2}$ & $p$ Value \\
\hline \multicolumn{9}{|l|}{ Age: } \\
\hline$\leqslant 35$ & $4.4(12)$ & $95.6(260)$ & \multirow[t]{4}{*}{163.1} & \multirow[t]{4}{*}{0.000} & $3.1(6)$ & $96.9(190)$ & \multirow[t]{4}{*}{169.5} & \multirow[t]{4}{*}{0.000} \\
\hline $36-45$ & $15.1(121)$ & $84.9(682)$ & & & $8.8(77)$ & $91.2(797)$ & & \\
\hline $46-55$ & $26.1(206)$ & $73.9(582)$ & & & $17.6(187)$ & $82.4(876)$ & & \\
\hline $56-65$ & $34.1(451)$ & $65.9(873)$ & & & $28.5(361)$ & $71.5(906)$ & & \\
\hline \multicolumn{9}{|l|}{ Job: } \\
\hline Manager & $25.0(406)$ & $75.0(1189)$ & \multirow[t]{2}{*}{0.0} & \multirow[t]{2}{*}{0.885} & $19.6(190)$ & $80.4(755)$ & \multirow[t]{2}{*}{0.8} & \multirow[t]{2}{*}{0.387} \\
\hline Subordinate & $24.8(311)$ & $75.2(979)$ & & & $18.1(362)$ & $81.9(1667)$ & & \\
\hline \multicolumn{9}{|l|}{ Employment: } \\
\hline White collar & $27.5(215)$ & $72.5(678)$ & \multirow[t]{2}{*}{3.9} & \multirow[t]{2}{*}{0.049} & $19.7(239)$ & $80.3(1190)$ & 1.6 & 0.216 \\
\hline Blue collar & $23.7(555)$ & $76.3(1686)$ & & & $17.9(381)$ & $82.1(1550)$ & & \\
\hline Mean work hours (h) & 9.4 & 9.5 & $1.6^{\star}$ & 0.200 & 8.6 & 8.7 & $0.9^{\star}$ & 0.336 \\
\hline Marital status: & & & & & & & & \\
\hline Married & $24.3(725)$ & $75.7(2166)$ & 5.9 & 0.017 & $18.4(586)$ & $81.6(2587)$ & 0.9 & 0.363 \\
\hline Unmarried & $30.1(62)$ & $69.9(224)$ & & & $21.3(43)$ & $78.7(170)$ & & \\
\hline Education: & & & & & & & & \\
\hline Less than compulsory & $24.7(357)$ & $75.3(896)$ & 0.1 & 0.740 & $20.7(346)$ & $79.3(1120)$ & 8.1 & 0.005 \\
\hline Higher & $24.4(428)$ & $75.6(1484)$ & & & $16.6(279)$ & $83.4(1641)$ & & \\
\hline Family history of hyperte & & & & & & & & \\
\hline Positive & $32.0(307)$ & $68.0(647)$ & 42.7 & 0.000 & $27.1(280)$ & $72.9(806)$ & 81.7 & 0.000 \\
\hline Negative & $21.2(442)$ & $78.8(1639)$ & & & $14.2(321)$ & $85.8(1879)$ & & \\
\hline Smoking: & & & & & & & & \\
\hline Never smoker & $24.9(181)$ & $75.1(508)$ & 4.3 & 0.041 & $18.2(569)$ & $81.8(2487)$ & 4.0 & 0.046 \\
\hline Ex-smoker & $27.9(239)$ & $72.1(544)$ & & & $22.6(11)$ & $77.4(69)$ & & \\
\hline Current $(\leqslant 20 /$ day $)$ & $22.8(259)$ & $77.2(879)$ & & & $26.4(39)$ & $73.6(167)$ & $\dagger$ & \\
\hline Current ( $\geqslant 21 /$ day) & $21.1(105)$ & $78.9(460)$ & & & - & - & & \\
\hline Alcohol intake (g/day): & & & & & & & & \\
\hline Never and ex-drinker & $18.6(131)$ & $81.4(531)$ & 21.9 & 0.000 & $17.8(427)$ & $82.2(1855)$ & 0.8 & 0.404 \\
\hline$<28.9$ & $24.0(204)$ & $76.0(703)$ & & & $19.1(168)$ & $80.9(816)$ & $\ddagger$ & \\
\hline $28.9-86.6$ & $26.3(336)$ & $73.7(894)$ & & & - & - & & \\
\hline$\geqslant 86.7$ & $30.4(85)$ & $69.6(209)$ & & & - & - & & \\
\hline Physical activity index: & & & & & & & & \\
\hline$\leqslant 28$ & $30.0(159)$ & $70.0(434)$ & 9.2 & 0.003 & $20.4(157)$ & $79.6(709)$ & 3.3 & 0.074 \\
\hline $29-36$ & $25.0(303)$ & $75.0(893)$ & & & $18.7(321)$ & $81.3(1374)$ & & \\
\hline$\geqslant 37$ & $22.7(320)$ & $77.3(1052)$ & & & $17.2(146)$ & $82.8(643)$ & & \\
\hline $\mathrm{BMI}\left(\mathrm{kg} / \mathrm{m}^{2}\right)$ : & & & & & & & & \\
\hline$<21.6$ & $14.9(148)$ & $85.1(827)$ & 125.1 & 0.000 & $11.8(117)$ & $88.2(988)$ & 102.0 & 0.000 \\
\hline $21.6-23.9$ & $23.0(253)$ & $77.0(858)$ & & & $15.1(173)$ & $84.9(963)$ & & \\
\hline$\geqslant 24.0$ & $35.7(376)$ & $64.3(679)$ & & & $27.9(329)$ & $72.1(787)$ & & \\
\hline Menopausal status: & & & & & & & & \\
\hline Postmenopausal & - & - & - & - & $20.3(475)$ & 79.7 (1449) & 0.9 & 0.375 \\
\hline Premenopausal & - & - & - & - & $7.5(145)$ & $92.5(1286)$ & & \\
\hline Job characteristics: & & & & & & & & \\
\hline Demand: & & & & & & & & \\
\hline Low & $23.6(242)$ & $76.4(718)$ & 1.7 & 0.206 & $18.9(206)$ & $81.1(837)$ & 0.0 & 0.895 \\
\hline Middle & $24.6(234)$ & $75.4(730)$ & & & $18.2(194)$ & $81.8(899)$ & & \\
\hline High & $25.9(314)$ & $74.1(949)$ & & & $18.7(231)$ & $81.3(1033)$ & & \\
\hline Control: & & & & & & & & \\
\hline High & $23.8(218)$ & $76.2(753)$ & 1.9 & 0.182 & $18.4(215)$ & $81.6(958)$ & 0.1 & 0.800 \\
\hline Middle & $24.1(243)$ & $75.9(777)$ & & & $18.4(222)$ & $81.6(979)$ & & \\
\hline Low & $26.6(329)$ & $73.4(867)$ & & & $18.8(194)$ & $81.2(832)$ & & \\
\hline Strain: & & & & & & & & \\
\hline Low & $22.2(227)$ & $77.8(771)$ & 8.8 & 0.003 & $19.1(219)$ & $80.9(885)$ & 0.0 & 0.974 \\
\hline Middle & $24.2(249)$ & $75.8(805)$ & & & $17.6(185)$ & $82.4(919)$ & & \\
\hline High & $27.6(314)$ & $72.4(821)$ & & & $18.9(227)$ & $81.1(965)$ & & \\
\hline
\end{tabular}

Values are age adjusted prevalence \% (n), except for age adjusted mean work hours. Comparisons among variables other than age were adjusted for age by the Mantel extension method for categorical variables and by analysis of covariance for work hours. ${ }^{\star} \mathrm{F}$ value.

†Those women who smoked cigarettes were rounded as current smokers irrespective of their amount of cigarettes they smoked per day.

¥Those women who drank alcohol were rounded as current drinkers irrespective of their amount of consumption.

hypertension was significant, whereas neither job control nor demands was significantly related to the prevalence of hypertension. In women, the associations between job characteristics and the prevalence of hypertension were inconsistent.

Table 3 shows the results of multiple logistic analyses. For men, age, marital status, family history of hypertension, alcohol intake, physical activity index, and body mass index were significantly and independently associated with the prevalence of hypertension. Job strain had a significant association with hypertension after adjusting for associated variables. Even after adjusting for all the possible confounders, including working conditions and education, the association remained significant (odds ratio (OR) 1.17 ; 95\% confidence interval (95\% CI)
1.04 to 1.32 ). In women, age, lower educational status, family history of hypertension, and body mass index were significantly associated with hypertension; however, the association between job strain and hypertension was not significant.

Table 4 shows the results of multiple logistic analyses based on four sociodemographic strata: manager or subordinate; white collar or blue collar worker; lower or higher than compulsory education level; and younger or older $(<55$ or $56-65)$ workers (all separated by sex). For men, each stratified category consistently showed an increased relative risk of job strain; but a significant excess risk of job strain was found for the categories of: subordinate, blue collar, lower educational attainment, and older age. Particularly, the differences between 
Table 3 Results of multiple logistic analysis

\begin{tabular}{|c|c|c|c|c|}
\hline \multirow[b]{2}{*}{ Variables } & \multicolumn{2}{|c|}{$\operatorname{Men}(n=2819)$} & \multicolumn{2}{|c|}{ Women $(n=3180)$} \\
\hline & $O R$ & $95 \% C I$ & $O R$ & $95 \% C I$ \\
\hline Age & 2.14 & 1.90 to 2.40 & 2.01 & 1.77 to 2.29 \\
\hline Employment & 0.90 & 0.72 to 1.13 & - & - \\
\hline Marital status & 1.58 & 1.10 to 2.26 & - & - \\
\hline Education & - & - & 1.30 & 1.07 to 1.59 \\
\hline Family history of hypertension & 1.76 & 1.45 to 2.14 & 2.44 & 2.01 to 2.98 \\
\hline Smoking & 0.94 & 0.86 to 1.03 & 1.21 & 0.99 to 1.48 \\
\hline Alcohol intake & 1.29 & 1.16 to 1.43 & - & - \\
\hline Physical activity index & 0.87 & 0.76 to 0.99 & - & - \\
\hline Body mass index & 1.87 & 1.65 to 2.11 & 1.82 & 1.61 to 2.07 \\
\hline Job strain & 1.18 & 1.05 to 1.32 & 1.01 & 0.90 to 1.13 \\
\hline
\end{tabular}

The reduced number of participants is due to selective missing data.

For men, age, employment, marital status, family history of hypertension, smoking, alcohol intake, physical activity index, body mass index, and job strain were included in the model.

For women, age, education, family history of hypertension, smoking, body mass index, and job strain were included in the model. Each factor adjusted for each other factor.

Age is coded from $1(\leqslant 35)$ to $4(56-65)$. Smoking habits are coded from 1 (never smoker) to 4 (smoked cigarettes $\geqslant 21 /$ day) for men, and from 1 (never smoker) to 3 (current smoker) for women. Alcohol intake is coded from 1 (never and ex-drinker) to 4 (drank $\geqslant 86.7 \mathrm{~g} / \mathrm{day}$ of alcohol). Physical activity index, body mass index and job strain are coded from 1 (the lowest level) to 3 (the highest level).

The OR values for variables with more than two categories were the ORs for each step.

Reference categories of the dichotomous variables are white collar workers, currently married, higher educational level, and no family history of hypertension.

Table 4 Odds ratios (95\% CI) of job strain on prevalence of hypertension according to sociodemographic characteristics, stratified by job, employment, education, and age

\begin{tabular}{|c|c|c|c|c|c|c|}
\hline \multirow[b]{2}{*}{ Categories } & \multicolumn{3}{|l|}{ Men } & \multicolumn{3}{|c|}{ Women } \\
\hline & $n$ & $O R$ & $95 \% C I$ & $n$ & $O R$ & $95 \% C I$ \\
\hline \multicolumn{7}{|l|}{ Job: } \\
\hline Manager & 1415 & 1.08 & 0.92 to 1.27 & 871 & 0.93 & 0.74 to 1.16 \\
\hline Subordinate & 1149 & 1.31 & 1.09 to 1.58 & 1919 & 0.99 & 0.85 to 1.15 \\
\hline \multicolumn{7}{|l|}{ Employment: } \\
\hline White collar & 821 & 1.11 & 0.90 to 1.37 & 1330 & 1.02 & 0.84 to 1.24 \\
\hline Blue collar & 1998 & 1.20 & 1.05 to 1.38 & 1820 & 1.01 & 0.87 to 1.17 \\
\hline \multicolumn{7}{|l|}{ Education: } \\
\hline Less than compulsory & 1067 & 1.21 & 1.01 to 1.45 & 1367 & 1.06 & 0.91 to 1.24 \\
\hline Higher & 1735 & 1.15 & 0.99 to 1.34 & 1813 & 0.94 & 0.79 to 1.11 \\
\hline \multicolumn{7}{|l|}{ Age: } \\
\hline$\leqslant 55$ & 1687 & 1.15 & 0.98 to 1.36 & 1997 & 1.02 & 0.86 to 1.22 \\
\hline $56-65$ & 1132 & 1.19 & 1.02 to 1.39 & 1183 & 0.99 & 0.84 to 1.15 \\
\hline
\end{tabular}

The reduced number of participants is due to selective missing data.

For men, age, employment, marital status, family history of hypertension, smoking, alcohol intake, physical activity index, and body mass index were adjusted for in the model. For the analysis in the employment strata, employment status was not included as an independent variable.

For women, age, education, family history of hypertension, smoking, body mass index were adjusted for in the model. For the analysis education was not included as an independent variable. Job strain is coded from 1 (the lowest level) to 3 (the highest level).

jobs (manager or subordinate) and employment (white or blue collar) were substantial. For women, no association between job strain and hypertension could be detected by the stratified analysis.

Although adjustment for occupation may lead to an overadjustment for the effect of job strain on health outcomes, ${ }^{14} 28$ adjustments were made for occupation in the final model. The magnitude of the association was slightly lower but remained significant (OR 1.14; 95\% CI 1.01 to 1.28 ).

The analyses were performed for each occupation. Relatively high ORs were found for male and female construction workers and male transport workers. For male construction workers, a significant OR was found despite the few cells (see appendices 1 and 2 for the job characteristics scores and the results of multiple logistic regression analyses for each occupation).

Multiple regression analyses were conducted to see the linear effect of the job strain index on mean systolic and diastolic pressures. In these analyses, adjustment was made for the use of antihypertensive medication as well as the other confounders noted. No significant associations were found.

\section{Discussion}

Job strain was positively associated with the prevalence of hypertension in Japanese men over a wide range of occupations. The excess prevalence amounted to $18 \%$ after adjustments for age, employment, marital status, family history of hypertension, smoking habits, alcohol intake, physical activity, and body mass index. With a crude assumption of the worst tertile job strain score defined as exposed, the aetiological fraction (population attributable risk) of the study population with hypertension was estimated to be $5.6 \%$, which, from a public health point of view, would not be negligible. ${ }^{1}$ As in other studies, only a combination of high demands and low control was related to the prevalence of hypertension. ${ }^{452029}$ The magnitude of the association seemed to be strongest for the lower social classes, where the level of job strain was higher than for their respective counterparts, and less so in the older age group. For the women in this sample, job strain was not associated with hypertension.

This sample seemed to underrepresent hypertension, perhaps because the invitation to participate in the study did not insist that those who were receiving care in hospitals and clinics for cardiovascular diseases should sign up with the others. However, this in itself is unlikely to produce a selective bias that would lead a normotensive worker who perceived his or her job as psychologically less demanding or one where the control was high to participate in the study. Observed associations between hypertension and behavioural variables other than job characteristics were similar to those reported in earlier epidemiological studies. ${ }^{30-33}$ Although the studied sample was not truly representative of the Japanese working population, these findings may reflect a profile of hypertension among Japanese workers.

One of the debates about the research methodology of the job strain model is: has the study population been selected from a few well chosen occupations or from a wide range of occupations? ${ }^{1}$ It is thought that a few well chosen occupations may be suitable for scrutinising specific job characteristics that affect workers' health in the selected occupations. Homogeneous samples may make it possible to illuminate the pure job strain effect on health outcome. However, the job demandcontrol questionnaire is often criticised as being too simple a tool to provide an adequate description of the psychosocial work environment. This low level of sophistication may not be powerful enough to produce a contrast in the exposure to stress within the small variance of a homogeneous sample. Occupation specific measures of job strain would be necessary to study a specific occupation in depth. ${ }^{34}$ Alternatively, in a diverse population such as this sample, a relatively wide variability of the stress level within the occupations is expected, which may increase the power to establish 
associations. Another advantage is the possibility of testing the job strain effect in several strata that the heterogeneity provides. Although only a weak association was found in our total sample, the stratified analyses showed some clear associations.

The finding of a job strain effect in male blue collar workers was similar to those obtained in recent studies, in which it was proved that the demand-control model is a more powerful predictor of cardiovascular disease in male blue collar workers than in their white collar counterparts. ${ }^{7536}$ The consistent finding about job and education may provide support for the notion that work related psychosocial factors explain the reported health disadvantage of populations from the lower social classes. $^{37}{ }^{38}$ The findings that even in Japan where the general belief is that there is relatively high homogeneity of wealth and health, show the importance of the social class issue in any analysis of job strain.

The association between job strain and hypertension seemed to be stronger in the older than in the younger age group. Because the study population was recruited from relatively rural communities, and changing occupation is unlikely (particularly in the older age group), this finding might indicate a cumulative effect of job strain on hypertension. ${ }^{6}$ However, because the oldest male category $(56-65,57.1 \%$ of the hypertensive men) accounted for most of the relation between job strain and hypertension, a definitive conclusion must await further studies.

Men and women may be affected differently by job characteristics. The sex differences found were unlikely to emerge from the difference in their stress related coping patternssuch as alcohol drinking ${ }^{59}$-because many lifestyle variables were adjusted for in the analysis. However, a sex difference may exist in the effectiveness of coping. ${ }^{40}$ The following, which might explain the sex differences, were not considered here: full time versus part time work, work preferences, and concepts about the value of work. ${ }^{41}{ }^{42}$ It should be noted that, according to the findings of this study, single male workers had a higher prevalence of hypertension than those who were married, which suggests that factors outside of work may affect the workers' health. Sex differences in the regulation of the sympathetic nervous system is another possible explanation. ${ }^{43}$

Appendix 1: Mean job characteristics scores according to occupation

\begin{tabular}{|c|c|c|c|c|c|c|c|c|}
\hline \multirow[b]{2}{*}{ Occupations } & \multicolumn{4}{|l|}{ Men } & \multicolumn{4}{|c|}{ Women } \\
\hline & $n$ & Demand & Control & Strain & $n$ & Demand & Control & Strain \\
\hline Farming & 954 & 11.2 & 17.0 & 0.67 & 1093 & 10.6 & 15.9 & 0.69 \\
\hline Fishery & 236 & 12.2 & 16.9 & 0.73 & 34 & 9.9 & 11.8 & 0.90 \\
\hline Guard & 19 & 9.1 & 13.2 & 0.71 & 1 & 10.0 & 15.0 & 0.67 \\
\hline Transport & 85 & 11.2 & 13.9 & 0.84 & 4 & 11.8 & 14.5 & 0.85 \\
\hline Construction & 607 & 12.4 & 16.9 & 0.76 & 84 & 10.8 & 12.9 & 0.88 \\
\hline Production & 336 & 12.4 & 16.5 & 0.78 & 654 & 11.6 & 13.0 & 0.92 \\
\hline Business & 247 & 11.7 & 17.5 & 0.68 & 356 & 10.5 & 16.0 & 0.67 \\
\hline Office work & 196 & 12.4 & 17.0 & 0.74 & 333 & 10.3 & 15.2 & 0.69 \\
\hline Professional & 199 & 12.6 & 18.0 & 0.71 & 193 & 11.3 & 16.2 & 0.72 \\
\hline Service industry & 251 & 11.8 & 17.2 & 0.69 & 547 & 10.7 & 14.6 & 0.76 \\
\hline
\end{tabular}

The magnitude of the association found was very weak: the linear analyses did not produce any significant associations. One of the reasons may be due to a methodological weakness - the use of casual blood pressure measurements for the outcome instead of ambulatory blood pressure monitoring. Previous studies indicate that ambulatory blood pressure monitoring is more sensitive for detecting an association. ${ }^{519} 2029$ In our study, blood pressure was measured at the person's health examination, not at his or her work site. Because a fully automated sphygmomanometer was used to measure blood pressure, observer errors in measurement were unlikely. The self reported history of hypertension and actual blood pressure levels were highly correlated. Thus substantial misclassification of the subjects was unlikely. However, particularly in occupational stress research, introducing ambulatory blood pressure monitoring in several situations (including at work) may make the association more precise, ${ }^{19} 2029$ which is difficult to do in large scale epidemiological studies.

The manner in which the psychological job characteristics are measured should be considered. The reliability and validity of the questionnaire on job characteristics were confirmed in other Japanese settings. ${ }^{23}{ }^{24}$ In this sample, too, the questionnaire was found to be internally consistent. Interrelations among the job characteristic scores, sex, and occupation were in concordance with previous studies. ${ }^{35} 4144$ However, the bias associated with self reporting is often criticised in job strain research. For example, those who are aware that their blood pressure is increased may let their health be affected by external work conditions. ${ }^{45}$ Because $50 \%-70 \%$ of our cohort members have undergone yearly medical examinations, most of the participants were presumably aware of their blood pressure levels. This may account for some bias. It should be noted that participants were asked questions about their job characteristics, not their feelings about stress. The demand-control model may relate more to objective measures of stressor than other questionnaires. ${ }^{46}$ Still, cultural differences may exist in reporting patterns for psychosocial measures. ${ }^{47}$ To confirm this, more objective measures, such as an average measure of job characteristics and measures by outside expert observers are needed. ${ }^{128}$ Although changing occupation is considered to be unlikely in the rural settings used here, the cumulative effects of job strain should be considered to confirm the results by using such a measure as the job exposure matrix..$^{48}$

Our findings provide limited support for the hypothesis that job strain is related to high blood pressure among Japanese male workers, which is independent of possible confounding factors. Male workers in the lower social classes and who are older seem to be more susceptible to the effect of job strain on hypertension. These populations may be target groups for further analyses or intervention. 
Appendix 2 Odds ratio $(95 \%$ CI) of job strain on prevalence of hypertension according to occupation

\begin{tabular}{|c|c|c|c|c|c|c|}
\hline \multirow[b]{2}{*}{ Occupations } & \multicolumn{3}{|l|}{ Men } & \multicolumn{3}{|c|}{ Women } \\
\hline & $n$ & $O R$ & $95 \% C I$ & $n$ & OR & $95 \% C I$ \\
\hline Farming & 824 & 1.19 & 0.97 to 1.47 & 941 & 0.95 & 0.77 to 1.18 \\
\hline Fishery & 211 & 0.82 & 0.52 to 1.28 & 31 & 0.19 & 0.02 to 2.08 \\
\hline Guard & 15 & - & - & 1 & - & - \\
\hline Transport & 75 & 1.90 & 0.65 to 5.55 & 3 & - & - \\
\hline Construction & 557 & 1.38 & 1.03 to 1.85 & 75 & 1.95 & 0.58 to 6.48 \\
\hline Production & 313 & 0.96 & 0.67 to 1.37 & 605 & 0.96 & 0.69 to 1.34 \\
\hline Business & 221 & 0.94 & 0.59 to 1.48 & 316 & 1.04 & 0.70 to 1.56 \\
\hline Office work & 181 & 1.26 & 0.78 to 2.02 & 300 & 1.00 & 0.60 to 1.67 \\
\hline Professional & 187 & 1.16 & 0.71 to 1.88 & 177 & 0.81 & 0.42 to 1.55 \\
\hline Service industry & 232 & 0.93 & 0.63 to 1.38 & 493 & 0.87 & 0.65 to 1.18 \\
\hline
\end{tabular}

The reduced number of participants is due to selective missing data.

For men, age, employment, marital status, family history of hypertension, smoking, alcohol intake, physical activity index, body mass index, and job strain were included in the model.

For women, age, education, family history of hypertension, smoking, body mass index, and job strain were included in the model. Each factor adjusted for each other factor.

Job strain is coded from 1 (the lowest level) to 3 (the highest level).

-Estimates could not be calculated.

This study was partly supported by the Foundation for the Development of the Community, Tochigi, Japan.

1 Kristensen TS. The demand-control-support model: methodological challenges for future research. Stress Med 1995;11:17-26.

2 Schnall PL, Landsbergis PA, Baker D. Job strain and cardiovascular disease. Annu Rev Public Health 1994;15: 381-411

3 Theorell T, Karasek RA. Current issues relating to psychosocial job strain and cardiovascular disease research. $\mathcal{f}$ Occup Health Psychol 1996;1:9-26.

4 Schnall PL, Pieper C, Schwartz JE, et al. The relationship between "job strain", workplace diastolic blood pressure, and left ventricular mass index: results of a case-control study. FAMA 1990;263:1929-35.

5 Schnall PL, Schwartz JE, Landsbergis PA, et al. Relation between job strain, alcohol, and ambulatory blood
pressure. Hypertension 1992;19:488-94.

6 Schnall PL, Schwartz JE, Landsbergis PA, et al. A longitudinal study of job strain and ambulatory blood pressure: results from a 3 year follow-up. Psychosom Med 1998;60: results from

7 Theorell T, Perski A, Åkerstedt T, et al. Changes in job strain in relation to changes in physiological state: a longitudinal study. Scand $\mathcal{F}$ Wrok Environ Health 1988;14:18996.

8 Kawakami N, Haratani T, Araki S. Job strain and arterial blood pressure, serum cholesterol, and smoking as risk factors for coronary heart disease in Japan. Int Arch Occup Environ Health 1998;71:429-32.

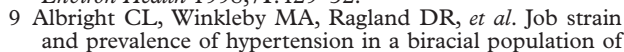
urban bus drivers. Am $\mathcal{F}$ Public Health 1992;82:984-9.

10 Chapman A, Mandryk JA, Frommer MS, et al. Chronic perceived work stress and blood pressure among Australian government employees. Scand $\mathcal{F}$ Work Environ Health 1990;
16:258-69.

11 Greenlund KJ, Liu K, Knox S, et al. Psychosocial work characteristics and cardiovascular disease risk factors in young adults. The CARDIA Study. Soc Sci Med 1995;41: young adil-23.

12 Seibt R, Scheuch K, Boucsein W, et al. Cardiovascular reactivity of different mental stress models in normotensives, borderline hypertensives and hypertensives. Stress Med 1998;14:183-93

13 Tarumi K, Hagihara A, Morimoto K. An inquiry into the relationship between job strain and blood pressure in male white-collar workers. Fpn F Ind Health 1993;35:269-76.

14 Marmot M, Theorell T. Social class and cardiovascular disease: the contribution of work. Int $f$ Health Serv 1988;18:659-74.

15 Marmot MG, Rose G, Shipley M, et al. Employment grade and coronary heart disease in British civil servants. $\mathcal{F}$ Epidemiol Community Health 1978;32:244-9.

16 Syme SL, Oakes TW, Friedman GD, et al. Social class and racial differences in blood pressure. Am $\mathcal{F}$ Public Health 1974;64:619-20.

17 Light KC, Turner JR, Hinderliter AL. Job strain and ambulatory work blood pressure in healthy young men and latory work blood pressure in healthy
women. Hypertension 1992;20:214-8.

18 Niedhammer I, Goldberg M, Leclerc A, et al. Psychosocial work environment and cardiovascular risk factors in an occupational cohort in France. $\mathcal{F}$ Epidemiol Community occupational cohort in
Health 1998;52:93-100

19 Theorell T, Ahlberg-Hulten G, Jodko M, et al. Influence of job strain and emotion on blood pressure in female hospital personnel during workhours. Scand $\mathcal{f}$ Work Environ Health 1993;19:313-8.
20 Van Egeren LF. The relationship between job strain and blood pressure at work, at home, and during sleep. Psychosom Med 1992;54:337-43.

21 Kario K, Nago N, Kayaba K, et al. Characteristics of the insulin resistance syndrome in a Japanese population. The Jichi medical school cohort study. Arterioscler Thromb Vasc Biol 1996;16:269-74.

22 Nago N, Kayaba K, Hiraoka J, et al. Lipoprotein(a) levels in the Japanese population: influence of age and sex, and relation to atherosclerotic risk factors-The Jichi medical school cohort study. Am f Epidemiol 1995;141:815-21.

23 Sugisawa A, Uehata T, Pin H, et al. Mental health, work environment, and health practices among middle-aged male workers. Fpn f Ind Health 1993;35:7-18. (In Japanese with English abstract.)

24 Tsutsumi A. The reliability and validity of the Karasek occupational stress scale (extended Karasek model) in a Japanese working population-the JMS cohort study. $\mathcal{F} p n \mathcal{F}$ Stress Sci 1994;9:109. (Abstract in Japanese.)

25 Kannel WB, Sorlie P. Some health benefits of physical activity: the Framingham study. Arch Intern Med 1979;139: 857-61.

26 Policy Planning and Research Department, Minister's Secretariat, Ministry of Labour. Handbook of labour statistics 1998. Tokyo: Printing Bureau, Ministry of Finance, 1998.

27 Ministry of Health and Welfare. National survey of circulating disorders, 1990. Osaka: Cardiovascular Research Foundation, 1993.

28 Kristensen TS. Job stress and cardiovascular disease: a theoretic critical review. f Occup Health Psychol 1996;1: 246-60.

29 Theorell T, de Faire U, Johnson J, et al. Job strain and ambulatory blood pressure profiles. Scand $\mathcal{F}$ Work Environ Health 1991;17:380-5.

30 Kornitzer M, Dramaix M, De Backer G. Epidemiology of risk factors for hypertension: implications for prevention and therapy. Drugs 1999;57:695-712.

31 MacMahon S, Cutler J, Brittain E, et al. Obesity and hypertension: epidemiological and clinical issues. Eur Heart f $1987 ; 8: 57-70$.

32 Ueshima H, Shimamoto T, Iida M, et al. Alcohol intake and hypertension among urban and rural Japanese populations. f Chron Dis 1984;37:585-92.

33 Watt GCM, Harrap SB, Foy CJW, et al. Abnormalities of glucocorticoid metabolism and the renin-angiotensin system: a four-corners approach to the identification of the genetic determinants of blood pressure. 7 Hypertens 1992;10:473-82.

$34 \mathrm{Kasl}$ SV. The influence of the work environment on cardiovascular health: a historical, conceptual, and methodological perspective. f Occup Health Psychol 1996;1:42-56.

35 Johnson JV, Hall EM. Job strain, workplace social support, and cardiovascular disease: a cross sectional study of a random sample of the Swedish working population. Am f Public Health 1988;78:1336-42.

36 Theorell T, Tsutsumi A, Hallqvist J, et al. Decision latitude, job strain, and myocardial infarction: a study of working men in Stockholm. Am ₹ Public Health 1998;88:382-8.

37 Bobák M, Hertzman C, Škodová Z, et al. Association between psychosocial factors at work and nonfatal myocardial infarction in a population-based case-control study in Czech men. Epidemiology 1998;9:43-7.

38 Marmot MG, Bosma H, Hemingway $\mathrm{H}$, et al. Contribution of job control and other risk factors to social variations in coronary heart disease incidence. Lancet 1997;350:235-9.

39 Lindquist TL, Beilin LJ, Knuiman MW. Influence of lifestyle, coping, and job stress on blood pressure in men and women. Hypertension 1997;29:1-7.

40 Christie MD, Shultz KS. Gender differences on coping with job stress and organizational outcomes. Work Stress 1998;12:351-61.

41 Hall EM. Gender, work control, and stress: a theoretical discussion and an empirical test. Int F Health Serv 1989;19: 725-45.

42 Mannheim B. Gender and the effects of demographics, status, and work values on work centrality. Work and Occupations 1993;20:3-22.

43 Hinojosa-Laborde C, Chapa I, Lange D, et al. Gender differences in sympathetic nervous system regulation. Clin Exp Pharmacol Physiol 1999;26:122-6.

44 Karasek R, Theorell T. Healthy work. Stress, productivity, and the reconstruction of working life. New York: Basic Books, 1990

45 Rostrup M, Ekeberg Ø. Awareness of high blood pressure influences on psychological and sympathetic responses. $\mathcal{F}$ Psychosom Res 1992;36:117-23.

46 Nyklícek I, Vingerhoets AJJM, Van Heck GL. Hypertension and objective and self-reported stressor exposure: a review. f Psychosom Res 1996;40:585-601

47 Iwata N, Roberts CR, Kawakami N. Japan-US comparison of responses to depression scale items among adult of responses to depression scale item
workers. Psychiatry Res 1995;58:237-45.

48 Johnson JV, Stewart WF. Measuring work organization exposure over the life course with a job-exposure matrix. Scand $\mathcal{F}$ Work Environ Health 1993;19:21-8. 


\section{LETTERS}

If you have a burning desire to respond to a paper published in Occupational and Environmental Medicine, why not make use of our "rapid response" option?

Log on to our website (www.occenvmed.com), find the paper that interests you, and send your response via email by clicking on the "eletters" option in the box at the top right hand corner.

Providing it isn't libellous or obscene, it will be posted within seven days. You can retrieve it by clicking on "read eletters" on our homepage.

The editors will decide as before whether to also publish it in a future paper issue.

\section{Musicians playing wind instruments and risk of lung} cancer: is there an association?

Lung cancer is an important public health problem. Tobacco is its main risk factor. Occupation is also an important risk factor. Some jobs have shown higher risks than others, but few investigations have asked about activities or hobbies in leisure time ${ }^{1}$ in relation to the risk of lung cancer.

A case-control study was performed between 1999 and 2000 in the Santiago de Compostela Health District (Galicia, northwest Spain). A total of 132 cases with confirmed diagnosis of lung cancer and 187 controls were enrolled. Controls underwent trivial surgery at the same hospital as did the cases. A personal interview about lifestyle and activities (past and present) was conducted by a trained researcher.

We found that, besides tobacco and occupational exposure to carcinogens, some leisure time activities were risk factors for lung cancer. ${ }^{1}$ Among the cases there were two musicians who played wind instruments, whereas there were no wind instrument players among the controls. The two cases had been playing the clarinet and trombone for 35 and 30 years respectively. Both were exsmokers (moderate smokers) and played music as a hobby. They had epidermoid lung cancer and were diagnosed at 57 and 76 years of age.

Since in our population the prevalence of persons playing musical instruments and specifically wind instruments is extremely low, we think that this activity might be a risk factor in development of lung cancer. The very low number of persons playing this type of musical instrument is probably a reason for the lack of studies focused on this activity, as many occupational studies of lung cancer and occupation are based on registries of workers. One study $y^{2}$ found an increased mortality rate of lung cancer for a category that included painters, potters, musicians, and actors-an inhomogeneous category that did not allow us to extrapolate results. The results were not adjusted according to smoking history.
This hobby requires inspiration and breathing of large volumes of air, making the lung alveoli expand more than in other people. This fact could facilitate the penetrance of carcinogens in the cells of the lung epithelium, and this could be more harmful in smokers. We have found no other studies that have reported this possible association. It would therefore be necessary to explore this association in greater samples of professionally exposed persons in order to ascertain whether this finding is consistent or due to chance.

A Ruano-Ravina, A Figueiras, J M Barros-Dios

Department of Preventive Medicine and Public Health, University of Santiago de Compostela,

Spain

Correspondence to: Dr J M Barros-Dios, Department of Preventive Medicine and Public Health, School of Medicine, C/ San Francisco s/n, Universidad de Santiago de Compostela, 15782 Santiago de Compostela, La Coruña, Spain; mrbarros@usc.es

\section{References}

1 Ruano-Ravina A, Figueiras A, Barros-Dios $J M$. Noxious exposures in leisure time and risk of lung cancer: A neglected exposure? Epidemiology 2002;13:235-6.

2 Minder CE, Beer-Porizek V. Cancer mortality of Swiss men by occupation, 1979-1982. Scand J Work Environ Health 1992;18/suppl 3).

\section{How important is personal exposure assessment in the epidemiology of air pollutants?}

The paper by Harrison and colleagues ${ }^{1}$ and the accompanying editorial by Cherrie $^{2}$ in the October 2002 issue of Occupational and Environmental Medicine address the important issue of personal exposure assessment (of air pollutants) in environmental epidemiology. After reading both papers we would like to make some comments with regard to the design, conduct and statistical analysis of the study by Harrison et al and at the same time answer the question raised by Cherrie in his editorial.

Coming from the occupational exposure assessment arena it is interesting to see that our environmental colleagues are still relying to a large extent on static (microenvironmental) sampling and even rely on shadowing to represent personal exposure. The latter brought back memories of old occupational hygiene textbooks with pictures of technicians standing with a sampling probe in the breathing zone of a worker (clearly hindered while carrying out his work task). It is interesting to note that Dr Cherrie's very relevant earlier work $^{3}$ on whether wearing sampling pumps affects exposure (it hardly did) was not mentioned in both papers.

The paper by Harrison and colleagues clearly states as one of its goals to answer the question "Does modelling through the use of microenvironment measurements and activity diaries produce reliable estimates of personal exposure to air pollutants". However, in the only setting where personal exposures were actually measured (phase 1, volunteers; with regard to phase 2 we do not think that shadowing results can be seen as equivalent to personally measured exposure) it is hard to grasp from both fig 1 and table 2 which exposure was actually modelled (1 hour averages,
2-3 day averages) and how (a formula was only provided for measurements within the susceptible groups).

When comparing direct personal measurements for $\mathrm{CO}$ and $\mathrm{PM}_{10}$ with the modelled results, the authors exclude all data which are not directly comparable-that is, when the volunteer spent most of their time out of house, and all the data for smokers. It is therefore not surprising that good correlations were found between personal and static measurement results. Why were smokers excluded? Was their measured CO exposure representing a different kind of CO leading to a different health effect? We know that excluding smokers or people with unventilated gas heaters is common practice in the statistical analyses of environmental exposures, but this would only make sense if we were expecting different risks from the same exposure originating from different sources.

In fig 1 the authors present 120 comparable data points for 11 individuals; given the repeated nature of the sampling these data points cannot be seen as statistically independent. Putting a simple regression line through these points is therefore not correct and application of a mixed effects model would have been more appropriate. Besides that, when estimating environmental exposure, for instance, for a panel study, we are interested in the full range of exposures both in the temporal and spatial sense (not only for the room with the static sampler). However, Harrison et al conclude, “... modelled personal exposure is unable to reflect the variability of measured personal exposures occasioned by the spread of concentrations within given microenvironments".

Both Cherrie and Harrison et al claim that microenvironmental sampling would be a good alternative for direct personal exposure measurements that supposedly are "costly and time consuming". However, the costs for sampling microenvironments in a general population study will be far greater if we want to measure all the microenvironments people end up in (for instance, in table l seven environments are indicated, and most of them will most likely be different for each study participant). In addition, it will be practically impossible to measure some of these environments as the authors point out. In their study, it was not possible to collect data for all appropriate microenvironments, even for a comparatively small number of subjects.

Recently, a very insightful paper was presented at the X2001 conference in Gothenburg. Seixas and colleagues ${ }^{4}$ showed that in a study to assess occupational noise exposure, a task based methodology (analogous to microenvironmental sampling in environmental exposure assessment) could only account for $30 \%$ of variability in daily exposures. They even considered this estimate somewhat optimistic since their estimated noise exposures were derived from the same data on which the daily average exposures were estimated. In addition they clearly pointed out that using simple task based averages that artificially compress exposure variability resulted in a very substantial negative bias in the estimated daily exposure.

In our opinion, we should aim to collect personal exposure measurements when estimating exposure for epidemiological studies. 
We agree that smaller and lighter sampling instruments will need to be developed, as was suggested by Cherrie in his editorial. Recent studies in both the occupational and environmental arenas have shown that study subjects are capable of carrying out personal measurements themselves (and by doing so, cutting out the costs of the technician). $)^{5-9}$ In all these studies except one, far more than 100 personal measurements were generated, which shows that studies of this size are not exceptional as was suggested in the editorial by Cherrie.

The question raised by Cherrie, "How important is personal exposure assessment in the epidemiology of air pollution?", can only be answered with a firm "very important", if we want to capture the full range of personal exposures experienced in the general environment. In addition, given the relatively low concentrations in the general environment, we will need to measure these accurately. Microenvironmental monitoring and consequent modelling based on diaries will not provide sufficient resolution and accuracy.

H Kromhout

Environmental and Occupational Health Division, Institute for Risk Assessment Sciences, Utrecht University, PO Box 80176, 3508 TD Utrecht, Netherlands; H.Kromhout@iras.uu.nl

$M$ van Tongeren

Centre for Occupational and Environmental Health, School of Epidemiology and Health Sciences, University of Manchester, Manchester, UK

\section{References}

1 Harrison RM, Thornton CA, Lawrence RG, et al. Personal exposure monitoring of particulate matter, nitrogen dioxide, and carbon monoxide, including susceptible groups. Occup Environ Med 2002;59:671-9.

2 Cherrie JW. How important is personal exposure assessment in the epidemiology of air pollutants? Occup Environ Med air pollutants? Occu

3 Cherrie JW, Lynch G, Bord BS, et al. Does the wearing of sampling pumps affect exposure? Ann Occup Hyg 1994:38:827-38.

4 Seixas N, Sheppard L, Neitzel R. Comparison of task-based and full-shift strategies for noise exposure assessment in the construction industry. Arbete och Hälsa 2001;10:51-3.

5 Kromhout H, Loomis DP, Mihlan GJ, et al. Assessment and grouping of occupational magnetic field exposure in five electric utility companies. Scand J Work Environ Health 1995;21:43-50.

6 Egeghy PP, Tornero-Velez R, Rappaport SM. Environmental and biological monitoring of benzene during self-service automobile refueling. Environ Health Perspect 2000;108: 1195-202.

7 Tielemans E, Heederik D, Burdorf A, et al. Assessment of occupational exposures in a general population: comparison of different methods. Occup Environ Med 1999;56:145-51.

8 Rijnders $\mathbf{E}$, Janssen NAH, Vliet PHN van, et al. Personal and outdoor nitrogen dioxide concentrations in relation to degree of urbanization and traffic density. Environ Health Perspect 2001;109:411-17.

9 Liljelind IE, Rappaport SM, Levin JO, et al. Comparison of self-assessment and expert assessment of occupational exposure to chemicals. Scand J Work Environ Health 2001;27:311-17.

\section{Will sewage workers with endotoxin related symptoms have the benefit of reduced lung cancer?}

Thorn and colleagues ${ }^{1}$ reported that sewage workers suffer from various symptoms which can be related to bacterial endotoxin (lipopolysaccharide) exposure. Other studies ${ }^{2-5}$ have shown that some members of this occupational group are commonly exposed to endotoxin. However, there appears to be a large discrepancy in endotoxin exposure among those categorised within this group. ${ }^{2}$ Endotoxin exposure to some of these workers appears to be sufficient to induce a respiratory response characteristically associated with endotoxin. ${ }^{2}$ Workers that have the highest exposure in sewage treatment are suggested to be associated with the waste treatment process. ${ }^{3}$ Professor Rylander pointed out that endotoxin exposure to this occupational group is low overall (personal communication with Professor Rylander). Rapiti and colleagues $^{6}$ suggested that the lack of an increased lung cancer rate in one study ${ }^{7}$ and reduced risk of lung cancer in another ${ }^{8}$ for sewage workers may be related to endotoxins in their occupational environment as was originally reported for cotton textile workers. ${ }^{9}$ Other studies ${ }^{10} 11$ that reported on lung cancer rates for sewage workers support these findings as suggested by Rapiti and colleagues. ${ }^{6}$ Rylander ${ }^{12}$ and Lange ${ }^{13}$ previously reviewed the epidemiological literature on reduced cancer rates in various occupations that are exposed to endotoxin.

A number of epidemiological, ${ }^{12-16}$ experimental, ${ }^{17}{ }^{18}$ and clinical ${ }^{19} 20$ studies have suggested that endotoxin is effective against cancer. A recent study in humans by Palmberg and colleagues ${ }^{21}$ reported that there is a rapid blood response of total leucocytes, monocytes, and granulocytes within seven hours followed by a dramatic decline within 24 hours. These findings are supported by an investigation by $\mathrm{O}^{\prime}$ Grady and colleagues ${ }^{22}$ in humans, in which endotoxin was instilled into a lung segment; increased tumour necrosis factor (TNF) and interleukin 1 were found in the bronchoalveolar lavage fluid 2-6 hours afterwards. Cytokine levels returned to normal concentrations within 24-48 hours after treatment. An increase of TNF in lung fluids as a result of exposure to endotoxin and dust containing endotoxin has been reported by others conducting human investigations as well, ${ }^{23}{ }^{24}$ including the suggestion of a dose-response relation. ${ }^{25}$ Thus, periodic exposure as would likely be experienced by those in sewage and dusty occupations may afford a continual or pulse stimulation of the immune system. Such stimulation may enhance production of anticancer mediator factors and cells ${ }^{26}$ that are suggested to be responsible for observed reduced lung cancer rates. ${ }^{13}$

Experimental studies ${ }^{27}$ have suggested that benefit of endotoxin exposure is most effective during initiation of lung cancer with a finding of less benefit for established tumours. This, together with results from Palmberg and colleagues, ${ }^{21}$ supports the hypothesis ${ }^{14} 27$ that endotoxin in an occupational setting is effective against the early formation of lung cancer. This further suggests that endotoxin reduces the incidence of lung cancer by stimulating the immune system to guard against early lung cancer events.

Additional studies are warranted on the relation of endotoxin and reduced lung cancer rates. This relation has been suggested for textile and agricultural workers. ${ }^{12-16}$ There is no reason to believe that it will not exist for other occupational groups exposed to endotoxin. Many have explained that the relation is not one of benefit, but rather methodology and bias, including differences in smoking rates. ${ }^{6-9}$ However, this explanation is not supported by experimental and clinical inves- tigations involving endotoxin. The major influence on lung cancer is tobacco use (smoking). Although smoking is identified as one of the reasons for lower than expected rates in some populations, some studies ${ }^{6-9}$ have shown that smoking is not always an explainable factor or bias for reduced lung cancer. For example, Rapiti and colleagues ${ }^{6}$ reported that the consumption of cigarettes and prevalence of smoking in a population of municipal waste workers was higher than the general population, but the incidence of cancer deaths (standardised mortality ratio) for lung cancer in this group was 0.55. Epidemiological studies need to include and report not only detrimental outcomes but also potentially beneficial associations. J H Lange
Envirosafe Training and Consultants, Inc., PO Box
114022, Pittsburgh, PA 15239, USA; john.pam.lange@worldnet.att.net

G Mastrangelo

Department of Environmental Medicine and Public Health, Section of Occupational Health, University of Padova, Via Giustiniani, 2-35128 Padova, Italy

K W Thomulka

University of the Sciences in Philadelphia, 600 South 43rd Street, Philadelphia, PA 19104, USA

\section{References}

1 Thorn J, Beijer L, Rylander R. Work related symptoms among sewage workers: a nationwide survey in Sweden. Occup Environ Med 2002;59:562-6.

2 Rylander R. Health effects among workers in sewage treatment plants. Occup Environ Med 1999:56:354-7

3 Lundholm M, Rylander R. Work related symptoms among sewage workers. Br J Ind Med 1983;19:325-9.

4 Thorn T, Kerekes E. Health effects among employees in sewage treatment plants: a literature survey. Am J Ind Med 2001;40:170-9

5 Laitinen S, Kangas J, Kotimaa M, et al. Worker's exposure to airborne bacteria and endotoxin at industrial wastewater treatment plants. Am J Ind Hyg Assoc 1994;55:1005-60.

6 Rapiti E, Sperati A, Fano V, et al. Mortality among workers at municipal waste incinerators in Rome: a retrospective cohort study. Am J Ind Med 1997;31:659-61.

7 Friis L, Edling C, Hagmar L. Mortality and incidence of cancer among sewage workers: a retrospective cohort study. $\mathrm{Br} J$ Ind Med 1993;50:653-7.

8 Lafleur J, Vena JE. Retrospective cohort mortality study of cancer among sewage workers. Am J Ind Med 1991;19:75-86.

9 Enterline PE, Sykora JL, Keleti G, et al. Endotoxin, cotton dust and cancer. Lancet 1985;2:934-5.

10 Friis L, Mikoczy L, Hagmar L, et al. Cancer incidence in a cohort of Swedish sewage workers: extended follow-up. Occup Environ Med 1999;56:672-3

11 Betemps EJ, Buncher CR, Clark CS. Proportional mortality analysis of wastewater treatment system workers by birthplace with comments on amyotropic lateral sclerosis. J Occup Med 1994;36:31-5.

12 Rylander R. Environmental exposures with decreased risks for lung cancer. Int J Epidemiol 1990;19:S67-S72.

13 Lange JH. Reduced cancer rates in agricultural workers: a benefit of environmental and occupational endotoxin exposure. Med Hypotheses 2000;55:383-5.

14 Mastrangelo G, Marzia V, Marcer G. Reduced lung cancer mortality in diary farmers: is endotoxin exposure the key factor? Am J Ind Med 1996;30:601-9.

15 Schroeder JC, Tolbert PE, Eisen EA, et al. Mortality studies of machining fluid exposure in the automobile industry IV: a case-control 
study of lung cancer. Am J Ind Med 1997:31:525-33.

16 Hodgson JT, Jones RD. Mortality of workers in the British cotton industry in 1968-1984. Scand J Work Environ Health 1990;16:113-20.

17 Lange JH. Anti-cancer properties if inhaled cotton dust: a pilot experimental investigation. J Environ Sci Health 1992;27A:505-14.

18 Lange JH. An experimental study of anti-cancer properties of aerosolized endotoxin: application to human epidemiological studies. J Occup Med Toxicol 1992;1:377-82.

19 Engelhardt R, Mackensen A, Galanos C. Phase 1 trial of intravenously administered endotoxin (Salmonella abortus equi) in cancer patients. Cancer Res 1991;51:2524-30.

20 Pance A, Reisser D, Jeannin JF. Antitumoral effects of lipid A: preclinical and clinical studies. J Investig Med 2002;50: 173-8.

21 Palmberg L, Larssson BM, Malmberg $P$, et al Airway response of healthy farmers and nonfarmers to exposure in swine confinement building. Scand J Work Environ Health 2002;28:256-63.

22 O'Grady NP, Presa HL, Pugin J, et al. Loca inflammatory responses following bronchial endotoxin instillation in humans. Am J Respir Crit Care Med 2001;163:1591-8.

23 Wang Z, Larsson K, Palmberg L, et al. Inhalation of swine dust induced cytokine release in the upper and lower airways. Eur Respir J 1997;10:381-7.

24 Jagielo PJ, Thorne PS, Watt JL, et al. Grain dust and endotoxin inhalation challenges produce similar inflammatory responses in normal subjects. Chest 1996; 110:263-70.

25 Michel O, Nagy AM, Schroeven M, et al. Dose-response relationship to inhaled endotoxin in normal subjects. Am J Respir Crit Care Med 1997; 156: 1 157-64.

26 Zhang M, Tracey KJ. Endotoxin and cancer. In: Brade H, Opal SM, Vogel SN, Morrison DC, eds. Endotoxin in health and diseases. New York: Marcel Dekker, 1999:915-26.

27 Lange JH, Sykora JL, Weyel DA, et al. An animal model for evaluating epidemiological evidence of anti-lung cancer activity of aerosolized cotton dust. In: Jacobs RR Wakelyn PJ, eds. Proceedings of the Eleventh Cotton Dust Research Conference, 7-8 January, National Cotton Council, Memphis, TN, 1987:93-6.

\section{Neurobehavioural testing in workers occupationally exposed to lead}

The article of Dr Goodman and coworkers on "Neurobehavioural testing in workers occupationally exposed to lead"1 covers an interesting approach with a surprising main message: "None of the individual studies is conclusive or adequate in providing information on the subclinical neurobehavioural effects ...". Such a sentence astonishes a reader since the studies used were selected from established journals.

A long section of the discussion deals with an article of Meyer-Baron and Seeber, ${ }^{2}$ the beforehand published meta-analysis on the topic. We agree that prospective studies are the best basis to receive a stable knowledge about exposure effects, also in neurobehavioural studies. However, the repeated information on cross sectional studies should also be accepted as source for conclusions on (neurobehavioural) effects due to exposures. Meta-analyses are one approach to search such summarising information.

Taking into account that the extended study selection in the article of Goodman et al may lead to different results we do not agree with several arguments. For example, they refer to the bias problem, the exposure range, the interpretation in terms of age related changes, and the results for the digit symbol test. On these problems an exchange of opinions has been published in Archives of Toxicology. ${ }^{3}$ Without making reference to this discussion, several arguments and conclusions were presented again. They are identical with the main conclusions in an anonymous "expert opinion" for the German Battery Association.

From our point of view it makes no sense to repeat the same details of argumentation for a second time. However, we believe that the readers of your journal should be informed that the conclusions of the article of Goodman et al have been discussed in other places. In the meantime an additional article on the subject has been published. ${ }^{6}$ In this article the data of the original "expert opinion" - the basis of the article in Occupational and Environmental Medicine - and the data of our first metaanalysis were comparatively evaluated. We hope that the critical readers of your journal pick up the full information on the matter. Thereupon they may draw their own conclusions regarding meta-analyses of neurobehavioural effects due to occupational exposure to inorganic lead.

\section{A Seeber, M Meyer-Baron} Institute for Occupational Physiology at the University of Dortmund, Ardeystraße 67, Dortmund, D-44139, Germany; seeber@ifado.de

\section{References}

1 Goodman M, LaVerda N, Clarke C, Foster ED, lannuzzi J, Mandel J. Neurobehavioural testing in workers occupationally exposed to lead: systematic review and meta-analysis of publications. Occup Env Med 2002;59:217-23

2 Meyer-Baron $M$, Seeber A. A meta-analysis for neurobehavioural results due to occupational lead exposure with blood lead concentrations $<70 \mu \mathrm{g} / 100 \mathrm{ml}$. Arch Toxicol 2000;73:510-18

3 Meyer-Baron M, Seeber A. Letter to the editor. Arch Toxicol 2001:75:441-2.

4 Goodman M, LaVerda N, Mandel J. Letter to the editor. Arch Toxicol 2001;75:439-40

5 Exponent. Neurobehavioral testing in workers occupationally exposed to lead: systematic review and meta-analysis of the published literature. Prepared for German Battery Association, central association of electrical engineering and electronics industry. Doc. No. SF29294.000 AOF00900.

Exponent, Menlo Park, September 2000.

6 Seeber A, Meyer-Baron M, Schäper M. A summary of two meta-analyses on neurobehavioural effects due to lead exposure. Arch Toxicol 2002;76:137-45.

\section{Authors' reply}

We thank Drs Seeber and Meyer-Baron for their comments on our paper, ${ }^{1}$ and also Drs Schwartz, Stewart, and $\mathrm{Hu}$ for comments published in the September 2002 issue of $O E M{ }^{2}$

The following is our response to the specific criticisms made by Schwartz and colleagues:

(1) "No evaluation of the quality of the evidence from available studies based on study design and analytical method." Study quality assessment was the first task we completed. As discussed in our methods section, our quality criteria included evaluating pre-exposure status, use of blinding procedures, and adjustments for age, other occupational exposures, alcohol use, and socioeconomic factors (income level, education, etc).

(2) "Data were combined from poorly done studies with data from well done studies." Table 1 shows that no study satisfied all of the above quality criteria. Schwartz et al did not provide criteria to distinguish a "poorly done" from a "well done" study. However, we conducted an additional analysis of the five relatively well designed studies that adjusted for age, education, and alcohol use (Baker and colleagues, ${ }^{3}$ Campara and colleagues, ${ }^{4}$ Chia and colleagues, ${ }^{5}$ Maizlish and colleagues, ${ }^{6}$ and Williamson and $\mathrm{Teo}^{7}$ ). These five allowed us to conduct a meta-analysis for only three tests. For the Santa Ana preferred hand test, the effect size changed from non-significant negative to non-significant positive. For the Santa Ana non-preferred hand the result changed slightly towards the null and remained statistically non-significant. For the digit symbol test, the result changed away from the null and remained statistically significant in the fixed effects model, but changed slightly towards the null and was no longer statistically significant in the two random effects models.

(3) "Inclusion of studies that did not control for age and education." Schwartz et al do not provide evidence that age and education are "the two most important predictors". One could argue that alcohol use or the presence of preexisting neuropsychiatric conditions could also act as powerful confounders. The studies in our meta-analysis had non-overlapping strengths and limitations and further inclusion or exclusion based on quality would be a matter of judgement. However, an additional analysis based on the 13 studies that adjusted for age and education revealed that, as opposed to our original findings based on all 22 studies, none of the tests showed a statistically significant difference in all three models. (See OEM website for results table.)

(4) "No adjustment for age, education, or lead dose differences across studies." This criticism appears to be somewhat theoretical, as the data did not allow such adjustment.

(5) "Reliance on exposed versus control comparisons" rather than "only including studies that reported beta coefficients for the blood lead versus test score relation, or adjusting for mean blood lead levels in exposed and non-exposed groups." We used the same definition of exposure as the previously published meta-analysis by MeyerBaron and Seeber ${ }^{8}$ (less than $70 \mu \mathrm{g} / \mathrm{dl}$ ) to find out if the results of our two studies were reproducible. The direct comparison of the two analyses in the discussion section was important in explaining our position with regards to meta-analysis as a research technique. We agree that other approaches could also be informative. The statement "The authors conclude that blood lead levels, that are described as 'moderate' in one location in the manuscript and 'low' in another, are not associated with neurobehavioral test scores" misrepresents our conclusions listed on page 222 of our paper.

(6) "Reliance on a small number of unspecified studies for effect estimates. Table 2 of the study reports the number of studies that were combined to derive effect estimates, but does not specify which studies were combined." The original version of the paper included information on each individual study; however, based on the reviewers' and editor's comments, we had to shorten the manuscript substantially. We will make this information available on request. With respect to the purported omission from our metaanalysis of the May 2001 article by Schwartz and colleagues, ${ }^{9}$ this article was unavailable when our manuscript was submitted for publication in December 2000. The other two studies they cite did not meet our inclusion criteria. While we have not had an opportunity to evaluate the association between cumulative exposure to lead and neurobehavioural testing results, we did note that the 
2001 article by Schwartz and colleagues ${ }^{9}$ found no association between tibia lead levels and test scores.

With regard to Seeber and Meyer-Baron's statements that "the repeated information on cross-sectional studies should also be accepted as source for conclusions on (neurobehavioural) effects due to exposures" and that "meta-analyses are one approach to search such summarising information", after having reviewed the results of five meta-analyses on the subject (two presented in the recent article by Seeber and colleagues, ${ }^{10}$ our paper, ${ }^{1}$ and the two additional re-analyses discussed here), we found five different sets of results with no evidence of consistency to qualify these results as "repeated". Therefore, we have to adhere to our original conclusions.

M Goodman, N LaVerda, C Clarke, E Foster, J Iannuzzi, J Mande

Exponent Health Group, 310 Montgomery Street, Alexandria, VA 22314, USA mgoodman@exponent.com

\section{References}

1 Goodman M, LaVerda N, Clarke C, et al. Neurobehavioural testing in workers occupationally exposed to lead: systematic review and meta-analysis of publications. Occup Environ Med 2002;59:217-23.

2 Schwartz BS, Stewart W, Hu H. Neurobehavioural testing in workers occupationally exposed to lead [letter]. Occup Environ Med 2002;59:648-9.

3 Baker EL, Feldman RG, White RA, et al. Occupational lead neurotoxicity: a behavioral and electrophysiological evaluation. Study design and year one results. $\mathrm{Br} J$ Ind Med 1984:41:352-61.

4 Campara P, D'Andrea F, Micciolo R, et al. Psychological performance of workers with blood-lead concentration below the current threshold limit value. Int Arch Occup Environ Health 1984;53:233-46.

5 Chia S-E, Chia H-P, Ong C-N, et al. Cumulative blood lead levels and neurobehavioral test performance. Neurotoxicology 1997; 18:793-804.

6 Maizlish N, Parra G, Feo O. Neurobehavioral evaluation of Venezuelan workers exposed to inorganic lead. Occup Environ Med 1995;52:408-14.

7 Williamson A, Teo R. Neurobehavioral effects of occupational exposure to lead. $\mathrm{Br} \mathrm{J}$ Ind Med 1986;43:374-80.

8 Meyer-Baron M, Seeber A. A meta-analysis for neurobehavioral results due to occupational lead exposure with blood lead concentrations $<70 \mu \mathrm{g} / \mathrm{ml}$. Arch Toxicol 2000;73:510-18.

9 Schwartz BS, Lee BK, Lee GS, et al. Associations of blood lead, dimercaptosuccinic acid-chelatable lead, and tibia lead with neurobehavioral test scores in South Korean lead workers. Am J Epidemiol 2001;153:453-64

10 Seeber A, Meyer-Baron M, Schäper M. A summary of two meta- analyses on neurobehavioural effects due to lead exposure. Arch Toxicol 2002;76:137-45.

\section{Ambient neighbourhood noise and children's mental health}

Readers may be interested to know that there are other recent studies that have provided equivocal evidence concerning the effects of environmental noise on children's mental health that have not been cited in the article by Lercher et al, published in the June 2002 issue of Occupational and Environmental Medicine. ${ }^{1}$ These new results need to be considered in the light of fact there has not been clear research evidence to support or dispute whether noise exposure in linked to mental health problems in children.
We have found inconsistent mental health results in our three recent studies examining the impact of aircraft noise on child health around Heathrow airport. ${ }^{2-4}$ In the West London Schools Study, ${ }^{4}$ aircraft noise was weakly associated with hyperactivity and psychological morbidity as measured by the Strengths and Difficulties Questionnaire $\left(\mathrm{SDQ}^{5}\right)$ completed by parents.

The SDQ is one of the most widely used psychometrically valid instruments to detect psychological morbidity in children in both the UK and internationally. However, in our other two studies using both the parent completed SDQ, the teacher completed Student Behaviour Checklist, and child self reported Depression (Child Depression Inventory, CDI) and Anxiety (Revised Child Manifest Anxiety Scale) we did not find any association between mental ill health and aircraft noise exposure. $^{23}$

The Austrian results should be placed within the context of existing studies with respect to two points: (1) the construct being measured in the Austrian study; and (2) the small effect size and inconsistency with previous research.

In the Heathrow studies we used internationally recognised child mental health screening tools, that have equivalent psychometric properties to the KINDL (only used in German speaking countries). It is worth noting that the KINDL is normally defined as a "valid and reliable index of quality of life", 6 rather than a sensitive screening tool to detect specific mental health problems. It is possible that the mental health results reported by Lercher and colleagues are tapping into impaired quality of life and wellbeing, rather than a precise mental health outcome such as "depression". The definition of "mental health" used by the authors needs to be clarified. The fact that the Austrian results do not replicate our Heathrow results raises the question: Does the KINDL measure wellbeing and quality of life rather than mental health? Furthermore, teacher reports of classroom adjustment would not normally be classified as a "mental health". Perhaps it might be more accurate to conclude from the Austrian research that: "ambient levels of noise in the community are associated with decreased quality of life and poorer classroom behaviour (rather than 'mental health') in elementary school children".

In summary, we feel that new research is necessary to provide further evidence about the effects of noise on child mental health. Even though Lercher and colleagues have taken the field of research forward with their two stage study design strategy, there is still more work to be done to clarify the terminology and measurement of mental health in the field of non-auditory health effects of noise. Specifically, a clear definitional and operational distinction needs to be made between stress/wellbeing/quality of life and mental health.

M Haines, S Stansfeld

Department of Psychiatry, Barts and the London Hospital, Queen Mary, University of London, London, UK Correspondence to: Dr M Haines, PricewaterhouseCoopers, 201 Sussex Street, GPO Box 2650, Sydney, New South Wales 1171 , Australia; mary.haines@au.pwcglobal.com

\section{References}

1 Lercher P, Evans GW, Meis M, et al. Ambient neighbourhood noise and children's mental health. Occup Environ Med 2002;59:380-6.
2 Haines MM, Stansfeld SA, Job RFS, et al. Chronic aircraft noise exposure, stress responses, mental health and cognitive performance in school children. Psychol Med 2001;31:265-77.

3 Haines MM, Stansfeld SA, Job RFS, et al. A follow-up study of the effects of chronic aircraft noise exposure on child stress responses and cognition. Int J Epidemiol 2001;30:839-45.

4 Haines MM, Stansfeld SA, Brentnall S, et al. West London Schools Study: the effect of chronic aircraft noise exposure on child chronic aircraft noise exposure on child
health. Psychol Medi 2001;31:1385-96.

5 Goodman R. A modified version of the Rutter Parent Questionnaire including extra items on children's strengths: a research note. Journal of Child Psychology and Psychiatry and Allied Disciplines 1994;35: 1483-94.

6 Evans GW, Hygge S, Bullinger M. Chronic noise and psychological stress. Psychol Sci 1995:6:333-8.

\section{No change in sex ratio in Ramsar (north of Iran) with high background of radiation}

A few areas of the world show high levels of natural radiation, and one of these areas is located in Iran. Ramsar is a northern coastal town situated in the Caspian littoral (in Mazandaran province, Iran) on the slopes of the Alborz mountain range, and surrounded by forests. It is situated at $49^{\circ} 40^{\prime}$ eastern longitude and $36^{\circ} 53^{\prime}$ northern latitude. The area is rich with mineral springs. Investigations into the amount of radium-226 in water started more than 30 years ago. ${ }^{1}$ It has been reported that inhabitants of Ramsar receive an annual radiation absorbed dose from background radiation that is up to $260 \mathrm{mSv}$, substantially higher than the $20 \mathrm{mSv}$ that is permitted for radiation workers. ${ }^{2}$

Annual births subdivided by gender, were obtained from Statistical Center of Mazandaran province. Because of the relatively small number of annual births in the urban area of Ramsar (currently about 670 per annum), analysis was carried out on the 11 year total for male and female live births, for the period 20 March 1989 to 19 March 2001, equal to Iranian calendar 1368 to 1379 Hejirae Shamsi (HS). The data was not available for the 1378 HS (equal to 20 March 1999 to 19 March 2000).

To test the null hypothesis that the probability of a male live birth in Ramsar is equal to that in the control populations, a $\chi^{2}$ test was conducted. A value of $\mathrm{p}<0.05$ was considered significant. The sex ratio is expressed as the proportion of total live births that were males.

The sex ratios at birth in the urban area of Tonekabon, the nearest city to Ramsar (about $20 \mathrm{~km}$ distance) and the urban areas of Mazandaran province (excluding Ramsar) were used as controls. The overall sex ratios in Ramsar, Tonekabon, and the urban areas of Mazandaran province were 0.511 (total live births $=7591), 0.517$ (total live births $=$ 14266), and 0.509 (total live births = 253 918), respectively. There was no significant difference between Ramsar and either Tonekabon $\left(\chi^{2}=0.95, \mathrm{df}=1, \mathrm{p}=0.33\right)$ or urban areas of Mazandaran province $\left(\chi^{2}=0.13, \mathrm{df}=1, \mathrm{p}=0.71\right)$

It has been reported that the sex ratio in the offspring of male radiologists is significantly lower than that in control populations. ${ }^{3}$ However, this is not consistent with the present result. This discrepancy could be attributed to the exposure of both parents to ionising radiation. Alternatively, because the inhabitants of Ramsar have lived for many generations in an area of high background radiation, 
some kind of adaptation might have occurred. This study was supported by Shiraz University

M Saadat

Department of Biology, College of Sciences, Shiraz University, Shiraz 71454, Iran saadat@susc.ac.ir

References

1 Khademi B, Mesghali A. Investigation and measurement of radium in Ramsar mineral water. Health Phys 1971;21:464-5.

2 Ghiassi-nejad M, Mortazavi SM, Cameron $J R$, et al. Very high background radiation areas of Ramsar, Iran. Preliminary biological studies. Health Phys 2002;82:87-93.

3 Hama Y, Uematsu M, Sakurai Y, et al. Sex ratio in the offspring of male radiologists. Acad Radiol 2001;8:421-4.

William Harvey and air pollution

Thomas Parr died, on 14 November 1635, at what was recorded as the advanced age of 152 years and 9 months. A postmortem examination was performed and a record made by William Harvey. A translation by Alan Muirhead of Harvey's account is included in the Everyman edition of De Motu Cordis. ${ }^{1}$ Parr seemed remarkably well preserved, and when considering the cause of death, Harvey identified air pollution as a possible contributory factor. His words are worth reading:

"It was consistent to attribute the cause of death to the sudden adoption of a mode of living unnatural to him. [Parr had been brought to London not long before he died by Lord Arundel.] Especially did he suffer harm from the change of air, for all his life he had enjoyed absolutely clean, rarefied, coolish, and circulating air, and therefore his diaphragm and lungs could be inflated and deflated and refreshed more freely. But life in London in particular lacks this advantage - the more so because it is full of the filth of men, animals, sewers, and other forms of squalor, in addition to which there is the not inconsiderable grime from the smoke of sulphurous coal constantly used as fuel for fires. The air in London therefore is always heavy, and in autumn particularly so, especially to a man coming from the sunny and healthy districts of Shropshire, and it could not but be particularly harmful to one who was now an enfeebled old man."

Harvey went on to point to the possible adverse effects of changing from a simple diet to a rich one. Harvey's observation on the possible effects of air pollution are interesting in that they antedate Evelyn's much better known analysis by 26 years. In retrospect we can see that Harvey identified the effects of short term exposure to high levels of air pollution on a vulnerable person.

R L Maynard

Department of Health, Skipton House, Elephant and Castle, London SE 1 6LH, UK; robert.maynard@doh.gsi.gov.uk

\section{Reference}

1 Harvey W. The circulation of the blood and other writings. Translated by Franklin KJ. Everyman's Library, No. 262. 1963. ISBN 0 460002627.

\section{Alternative methods of administering amyl nitrite to victims of cyanide poisoning}

The traditional method of administering amyl nitrite to a victim of cyanide poisoning, is to break an ampoule in a handkerchief and then intermittently hold this under the victim's nose. ${ }^{12}$

I would like to suggest two alternative methods for administering amyl nitrite. The first method is to use a nebuliser. The second method is to use an inhaler similar to the Penthrox device, normally used to administer methoxyflurane for emergency analgesia.

With appropriate training, either method could be used by first aid staff. This could be of particular value to remote mine sites where the absence of medical staff may preclude intravenous administration of cyanide antidotes such as dicobalt edetate, sodium thiosulphate, sodium nitrite, or hydroxocobalamin.

Both methods offer the following advantages over the traditional method:

- Oxygen can be administered during treatment

- Rapid delivery of the drug

- Accurate dose delivery

- Less risk of inhalation by first aid or medical staff

- Less risk of injury due to glass fragments.

The inhaler device would also be particularly well suited to the treatment of large numbers of victims following industrial disaster or terrorist attack-the risk of which has been recently alluded to.

One concern about introducing these methods is the potential for amyl nitrite toxicity. Experimental research is recommended to determine safe dosages and frequencies for each method.

A M Donoghue

School of Public Health, Queensland University of Technology, Victoria Park Road, Kelvin Grove, Brisbane QLD 4059, Australia m.donoghue@qut.edu.au

\section{References}

1 Baxter PJ. Gases. In: Baxter PJ, Adams PH, Aw TC, et al, eds. Hunter's diseases of occupations, 9th edn. London: Arnold, 2000: 145-6.

2 Zenz C, Cordasco EM. Hydrogen cyanide and cyanide salts. In: Zenz C, Dickerson OB, Horvath EP, eds. Occupational medicine, 3rd edn. St Louis: Mosby, 1994:672-4.

3 Saver SW, Keim ME. Hydroxocobalamin: improved public health readiness for cyanide disasters. Ann Emerg Med 2001;37:635-41.

\section{BOOK REVIEWS}

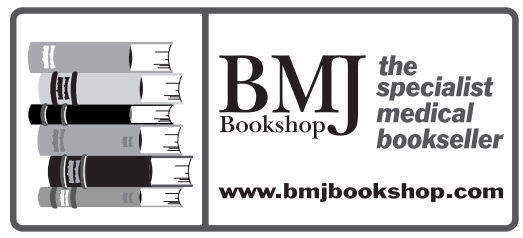

\section{Basic Statistics and Epidemiology, A Practical Guide}

Antony Stewart (pp 151; £19.95) 2002 Oxford: Radcliffe Medical Press. ISBN I 857755898

This book is "aimed at people who want to understand the main points, with minimum fuss"-no small task when the subject at hand is statistics! However, this book manages it by using short, concise, easy to read chapters that contain simple examples and a minimum of mathematics. The style is suitable both as a text to read from start to finish and as a reference book. It introduces students to the basic terms and concepts in statistics and epidemiology and provides a very basic "walk through" of some simple formulae.

The book is loosely divided into two parts. It begins with a brief description of what are statistics, their role in the study of populations, and ways in which samples can be drawn from populations in order to make statements about individuals in the population. Concepts such as probability, significance testing, and standard errors are introduced and explained before a very brief mention of some simple statistical tests. In these later chapters insufficient information is provided to allow the reader to understand the mechanisms of these tests, or the conditions required for their application. However, useful references are given where the reader may find further detail.

In the second "half" of the book the author covers basic epidemiological concepts, describing the difference between prevalence and incidence, and how to measure disease frequency, and discussing bias and confounding. Later chapters in this section introduce basic study designs such as cohort, casecontrol, and randomised clinical trial (or RCT), and describe the planning and use of questionnaires.

The book provides a useful glossary of terms, including mathematical symbols and a number of statistical tables. A set of exercises is given and answers are provided. These are an invaluable addition to the book.

For the non-mathematical health student faced with the daunting prospect of having to begin studying statistics, this 150 page book is an excellent primer. It introduces basic terms and concepts and gets the student started. However, statistical concepts can be difficult to understand, and in some chapters in this book the brief introduction given falls short of helping the student understand the concepts properly. Therefore the interested student may see this book as a first introductory text, shortly to be followed or indeed accompanied by a more full statistical or epidemiological textbook. For this purpose an excellent, current bibliography is provided.

R Atkinson

\section{Occupational Disorders of the Lung: Recognition, Management and Prevention}

David J Hendrick, P Sherwood Burge, William S Beckett, Andrew Churg (pp 638; £99.99) 2002. London: WB Saunders. ISBN 07020 25070

The authors of this book aim to draw attention to "the changing nature of the contribution the occupational environment makes to lung disease, and to the particular difficulties this poses for those who find themselves responsible for patient care or the management of relevant industries". The result is a book which is easy to read, helped greatly by use of a standard format for each chapter. The format includes management of both the individual and the workforce, and prevention. The authors have also used difficult or "grey" cases, similar to one other textbook in the field. The difference here is 
that the cases were circulated to all the contributors to this volume and the overal response summarised in the text. The lack of complete agreement in many instances is comforting at one level— "textbook" cases are the exceptions in practice- and this approach gives a far better feel for the real life situation.

Another attractive feature of this book is the chapters dedicated to descriptions of certain industries and the problems that arise from those workplaces, including mining farming, the automotive industry, and health carers among the seven chapters. This does lead to repetition of some information between chapters but, as the authors rightly point out, readers will tend to dip into one particular part of the book, and repetition under these circumstances is helpful rather than an irritation. The chapters on specific disciplines used in the investigation and management of occupational lung disease (for example, imaging and occupational hygiene) are good and sufficient for most needs in this context. The chapters on legislation divided geographically into North America Western Europe, and the Pacific, Far East, and Australasia is an excellent attempt to widen the relevance of the book.

My criticisms are few and minor. While there are good generic sections on how to take an occupational exposure history and on surveillance, it might have been a useful addition to include a chapter on epidemiological aspects unrelated to surveillance and more to the research field. This would allow greater expansion on the healthy worker effect and perhaps also the opportunity to compare the now burgeoning literature on the health effects of the broader environment and how these findings might apply to the occupational scene. Boxes have been used for specific sections within chapters. Sometimes this works, but sometimes it does not. There are one or two boxes which run to four or five pages and I feel that these would quite happily sit as sections within the chapte rather than boxes. Boxes need to be short and punchy.

This book is an excellent addition to the literature in this area, complimenting nicely the classical standard textbooks, and at a penny under $£ 100$ is good value for money. It is targeted at all physicians, hygienists, health and safety officers, and administrators, and successfully hits that target for all these groups. For exam purposes (for example, AFOM in the UK) this should be regarded as the standard text.

J G Ayres

\section{Bone's Atlas of Pulmonary and Critical Care Medicine, 2nd edition}

Edited by G Douglas Campbell Jr and D Keith Payne (pp 315 plus index and colour plates; \$95) 2001. Haggerstown, MD: Lippincot Williams \& Wilkins. ISBN 0781734363

This book aims to cover an enormous subject, and the editors have done very well to contain it to a little over 300 pages. Its 26 chapters are grouped into six sections, the lion's share being occupied by respiratory topics, with critical care being limited to the relatively short final section. The atlas format is certainly stylish and on the whole achieves the editors' aim-that is, of helping busy clinicians and students of chest disease absorb a large amount of information in a relatively short amount of time.

Despite the numerous contributors, the book's layout is uniform and very accessible; text is limited and punchy and extensive use has been made of diagrams, flow charts, and tables to supplement the generally good quality photographic images. The grouping of the colour plates to the final pages of the book, to contain printing costs, is a little distracting but a justifiable compromise.

All of the material is up to date and well referenced, though tends to some extent to be dominated by North American sources and opinion. I found the chapters dealing with lung cancer, bronchiolitis obliterans and other bronchiolar airway disorders, and sarcoidosis to be particularly useful and excellent sources of a large and diverse amount of information. In contrast the chapter dealing with interstitial lung disease was to me a little disappointing. The chapters covering sleep disorders, HIV and fungal infections, lower respiratory tract infections, and nutrition are new to this edition and are welcome additions. The use of graded evidence based recommendations for diagnostic and therapeutic interventions is variable between chapters and its more consistent application would add further to this book's already considerable value.

I am sure this atlas will have broad appeal to both undergraduate and postgraduate students of chest medicine as well as busy practitioners. It would be a valuable aid to those preparing for postgraduate exams as well as to specialist registrars in respiratory medicine who I'm sure would find it a very useful source throughout their trainee years. Intensivists and trainees in critical care will, I expect, find the balance towards respiratory medicine less appealing. It has few competitors in terms of its breadth and clarity and it represents good value for money; in short it deserves a place in all good medical libraries.

W S Tunnicliffe

\section{The Health Effects of Chrysotile Asbestos}

R P Nolan, A M Langer, M Ross, F J Wicks, R F Martin (pp 304, \$38) 2001. Ottaza Ontario: The Canadian Mineralogist. ISBN 0 921294417

The famous mortality study led by Corbet McDonald has followed 11000 Canadian chrysotile miners and millers until $80 \%$ were dead; only 33 mesotheliomas were reported and excess lung cancers occurred only at very high exposure levels. Yet that same chrysotile used in textile manufacture in South Carolina was associated with a 50 times greater lung cancer mortality.

This volume, published in 2001 by The Canadian Mineralogist, reports the papers presented and the ensuing discussion and commentary at a symposium in 1997 called by the Canadian Government to discuss the health issues surrounding the continued production and use of chrysotile asbestos. Can the mineral be used safely? To most uninformed observers, the answer must be a clear no. The true answer is of course not so clear cut. Much of the evidence suggests that chrysotile itself is much less hazardous than the amphiboles and that the serious risks associated with chrysotile are a consequence of its contamination by tremolite, an amphibole that is found in geological intrusions into the chrysotile ore body. These are the issues discussed by the distinguished geologists, mineralogists, epidemiologists, risk analysts, and pathologists who contributed to the symposium. Among them are the last published contributions of two who made great contributions over many decades to investigating the hazards of asbestos and to protecting workers, the late Chris Wagner and Bob Murray.

The resolution of this conundrum may seem unimportant to those who live in countries where past exposures have been to mixtures of amphiboles and chrysotile and where use of asbestos has effectively ceased. However, industry continues to need durable fibres and the poor world sees substantial advantages in using cheap asbestos cement for water pipes and roofing material. And the issue is of course important to the Canadian and Russian chrysotile industries and their employees. Anyone who has been involved in the asbestos debate, who gives advice to industry or lawyers on asbestos issues, or who is interested in the complexities of the interface between science and regulation will find much of fascination in this volume.

A Seaton

\section{NOTICES}

\section{First World Congress on}

Work-Related and

\section{Environmental Allergy (1st}

WOREAL), and Fourth

International Symposium on Irritant Contact Dermatitis (ICD), Helsinki, Finland, 9-12 July

2003

Congress on Work-Related and

Environmental Allergy

- Work related and environmental aspects of respiratory and skin allergy

- Specific issues related to pathophysiology and skin allergy

- Management and prevention of allergy

Irritant Contact Dermatitis Symposium

- Occupational irritant dermatitis

- Prevention of irritant dermatitis

- Alternative methods for the assessment of irritants

- Irritant dermatitis from cosmetics

Satellite events

- Satellite Symposia, 9 July 2003

- Allergy School, 9-10 July 2003

- 7th International NIVA Course on WorkRelated Respiratory Hypersensitivity, 11-15 July 2003

\section{Congress Secretariat}

Ms Kirsi Saarelma, Congress Manager

Pyykkö \& Saarelma Ltd

Limingantie 9

FIN-00550 Helsinki, Finland

Tel: +3589790080

Fax: +35897573630

Email: secretariat@woreal.org

Website: www.woreal.org 


\section{NIVA Training Programme 2003: Advanced Courses in Occupational Health and Safety}

NIVA Training Programme 2003 offers 12 advanced courses on current themes of work life. Further information is available from the NIVA Office:

NIVA Nordic Institute for Advanced Training in Occupational Health

Topeliuksenkatu 41 a A

FIN-00250 Helsinki

Finland

Tel: +358947471

Fax: +35894747 2497, +35892414634

Email:niva@ttl.fi

Website: www.niva.org

Assessment of Psychological Factors at Work 3-6 March 2003, Geilo Hotel, Geilo, Norway

Evaluation and Good Occupational Health Practice

23-27 March 2003, The Fell Hotel, Saariselkä (Lapland), Finland

Principles of Etiologic/Etiodiagnostic

Research

11-16 May 2003, Hanasaari Cultural Center

Espoo (Helsinki), Finland

Toxicokinetic and Toxicodynamic Modeling in Occupational Health

15-19 June 2003, Red Cross Educational Training Center, Gripsholm, Sweden
Work-related Respiratory Hypersensitivity 10-15 July 2003, Marina Congress Center, Helsinki South Harbour, and The Sunborn Yacht Hotel, Naantali, Finland

Bullying and Harassment at Work

11-15 August 2003, Hotel Eckerö, Åland, Finland

Good Management Practice-Interaction of Environment, Safety and Quality

31 August-4 September 2003, Hotel Levitunturi, Sirkka (Lapland), Finland

Workplace Health Promotion-Practice and Evaluation

The first part 15-17 September 2003, Hotel Eckerö, Åland, Finland and the second part 19-21 January 2004, The Nordic School of Public Health, Gothenburg, Sweden

Indoor Air Quality Problems - Link between Indoor Pollution, Psychological Factors and Complaints

22-26 September 2003, Vilvorde Course Center, Vilvorde (Copenhagen), Denmark

Occupational Health Risk Assessment and Management

6-10 October 2003, Medical Academy of Latvia, Riga, Latvia

Introduction to Occupational Epidemiology 23-29 October 2003, Hotel Gentofte (Copenhagen), Denmark
Work-related Musculoskeletal Disorders:

Current Research Trends

1-7 November 2003, The Sunborn Yacht Hotel, Naantali, Finland

\section{CORRECTIONS}

The authors of "Association between job strain and prevalence of hypertension: a cross sectional analysis in a Japanese working population with a wide range of occupations: the Jichi Medical School Cohort Study" (Tsutsumi A, Kayaba K, Tsutsumi K, Igarashi M, Occup Environ Med 2001;58:367-7) have asked for the following errors to be pointed out.

- There are errors in the abstract (line 16) and text (page 368, left hand column, line 5). A part of the baseline data was collected in 1995 in two of the 12 study sites so that the correct period was 1992-95 (not 199294).

- On page 368 , left hand column, line 24 , the number of older participants (over 69) should be 696 and not 699 .

These facts do not, however, affect the study findings.

We apologise for the following error in the book review, "Late lessons from early warnings: the Precautionary Principle 1896-2000" by R L Maynard. A copy of this book is available to download free of charge from EEA Online. The URL, however, was published incorrectly. The correct link is: http:// reports.eea.eu.int/

environmental issue report 2001 22/en. 